\title{
Comparative Study on Malaria Preventive Practices among Under-Five Children in Three States in South-South Nigeria
}

\author{
N. I. Paul ${ }^{1}$, A. T. O. Awopeju ${ }^{2 *}$, I. N. Chijioke-Nwauche ${ }^{3}$, T. Kasso', I. L. Oboro ${ }^{2}$, L. E. Yaguo-Ide', \\ G. Otto ${ }^{5}$, M. Ogoro 6 , O. Maduka7, C. Abam ${ }^{8}$, C. A. Nwauche ${ }^{8,9}$ \\ ${ }^{1}$ Department of Paediatrics and Child Health, University of Port Harcourt, Port Harcourt, Nigeria \\ ${ }^{2}$ Department of Medical Microbiology, University of Port Harcourt, Port Harcourt, Nigeria \\ ${ }^{3}$ Department of Clinical Pharmacy and Management, University of Port Harcourt, Port Harcourt, Nigeria \\ ${ }^{4}$ Department of Obstetrics and Gynaecology, University of Port Harcourt, Port Harcourt, Nigeria \\ ${ }^{5}$ Department of Economics, University of Port Harcourt, Port Harcourt, Nigeria \\ ${ }^{6}$ Department of Geography \& Environmental Management, University of Port Harcourt, Port Harcourt, Nigeria \\ ${ }^{7}$ Department of Preventive and Social Medicine, University of Port Harcourt, Port Harcourt, Nigeria \\ ${ }^{8}$ Department of Haematology, Blood Transfusion and Immunology, University of Port Harcourt, Port Harcourt, Nigeria \\ ${ }^{9}$ Malaria Elimination \& Phytomedicine Research, University of Port Harcourt, Port Harcourt, Nigeria \\ Email: *abimbola.awopeju@uniport.edu.ng
}

How to cite this paper: Paul, N.I., Awopeju, A.T.O., Chijioke-Nwauche, I.N., Kasso, T., Oboro, I.L., Yaguo-Ide, L.E., Otto, G., Ogoro, M., Maduka, O., Abam, C. and Nwauche, C.A. (2020) Comparative Study on Malaria Preventive Practices among Under-Five Children in Three States in South-South Nigeria. International Journal of Clinical Medicine, 11, 70-83. https://doi.org/10.4236/ijcm.2020.112008

Received: January 14, 2020

Accepted: February 17, 2020

Published: February 20, 2020

Copyright ( 2020 by author(s) and Scientific Research Publishing Inc. This work is licensed under the Creative Commons Attribution International License (CC BY 4.0).

http://creativecommons.org/licenses/by/4.0/

\begin{abstract}
Background: Malaria has remained one of the leading causes of morbidity and mortality in children despite effective preventive and treatment modalities. This study is aimed at looking at the malaria preventive practices among under-five children in three Niger Delta states in Nigeria and comparing the differences among them if any. Methods: This was a cross sectional study carried out over six months from $1^{\text {st }}$ January to $30^{\text {th }}$ June 2019 in public health facilities among under-five children in three South-South states (Akwa Ibom, Delta and Rivers) of Nigeria. Using a stratified sampling method, children were recruited from 36 health facilities in the three states. A pretested interviewer administered questionnaire was used to harvest relevant information on socio-demographic characteristics of the subjects and informants and malaria preventive practices. Obtained data was analysed using SPSS version 22 and results are presented in prose and frequency tables. Chi-square and Fischer's exact were used for comparison of categorical variables, while a p-value of $<0.05$ was considered statistically significant. Results: A total of 3144 children participated in the study: 1661 (52.8\%) were males while 1483 (47.2\%) were females. Children less than 2 years represented $77.6 \%$ of the study participants while the mean age was $1.72 \pm 1.06$ years. Mothers constituted over $80 \%$ of the informants in all the states. More of the informants had
\end{abstract}


secondary education in Akwa Ibom and Delta states, while in Rivers state, more of them had tertiary education. Malaria prevention method practiced in the three states included; use of insecticide treated bed net (ITNs), insecticide spray, anti-malarial drugs, clearing of bushes and disposal of mosquito breeding cans and use of mosquito repellents. Indoor residual spraying (IRS) was not practiced in any of the states. Use of ITN was practiced more in Rivers state (53.2\%) than in Delta (20.3\%) and Akwa Ibom (8.2\%) states, while use of insecticide spray was commoner in Akwa Ibom state (77.2\%) than in Delta (56.3\%) and Rivers (42.4\%). This difference in the prevention techniques practiced among the states was statistically significant (Fischers exact $-724.2, \mathrm{p}$-value $=0.0001)$. Conclusion: In conclusion, the practice of ITNs use is low in South-South Nigeria with IRS not being practiced at all. Introduction of IRS as a method of malaria vector control and public health education on ITNs ownership and use is advocated.

\section{Keywords}

Malaria, Preventive-Practices, Under-Five-Children, South-South Nigeria

\section{Introduction}

Malaria is a protozoan infection in humans caused by the parasite Plasmodium. It is a life-threatening vector borne infection and children under 5 years and pregnant women are the most vulnerable group in endemic areas. Malaria is essentially a disease of the tropics and subtropics particularly the sub-Saharan African region although it can be found in temperate areas due to migration from the tropics. Over $90 \%$ of the world's malaria occurs in sub-Saharan Africa and about 500 million cases are recorded annually; a child under the age of 5 years is said to die from malaria in every 2 minutes [1] [2]. Malaria has continued to be one of the leading causes of morbidity and mortality in children despite effective preventive and treatment modalities and more than $20 \%$ of world's population are affected by malaria [3]. The morbidity and mortality from malaria are still unacceptably high in the developing countries, especially among the vulnerable group, despite all control efforts.

Malaria remains a public health problem facing developing countries and $\mathrm{Ni}$ geria being the most populous African country bears a very high percentage of this burden. Nigeria accounts for $25 \%$ of global malaria burden [4] and being the eighth most populous country in the world, the burden of malaria in Nigeria is conversely a world burden especially with the level of migration of Nigerians particularly to the western world. The UK Health Protection Agency [5] states that about 1614 malaria cases were reported in the UK yearly between 2005 and 2010 , and $22 \%$ of these cases in 2010 were from Nigeria. Estimate shows that over $50 \%$ of Nigerians suffer at least about of malaria every year [3]. And malaria accounts for $20 \%$ and $25 \%$ of under-five mortality and childhood mortality re- 
spectively and this constitutes a huge economic burden [1] [6] [7].

Malaria is holo-endemic in Nigeria with transmission all the year round. Nigeria has two main seasons in the year, the dry season which is from October to about March and the rainy season which is from April to September with peak of the rains between May and July when malaria transmission is very intense. Rainfall pattern in Nigeria varies with the South having more rains than the North. Annual rainfall decreases northward; rainfall ranges from about 2000 millimeters in the coastal zone (averaging more than 3550 millimeters in the Niger Delta) to 500 - 750 millimeters in the north. The far south is defined by its tropical rainforest climate, where annual rainfall is 60 to 80 inches (1524 to 2032 $\mathrm{mm}$ ) a year. The Niger Delta is located on the Atlantic coast of Southern Nigeria encompassing an area of $20,000 \mathrm{~km}^{2}$ and it is the world's third largest wetland [8]. The mangrove swamp forest vegetation encourages all-year-round transmission of malaria in this area.

The knowledge of the preventive measures of malaria is an important preceding factor for the acceptance and use of malaria preventive practices [9]. Surveys of residents of the Atlantic coast revealed a lack of knowledge and many misconceptions about the transmission and treatment of malaria, which could adversely affect malaria preventive practices and treatment [3] [10]. Prevention of malaria is currently based on two complementary methods: chemoprophylaxis especially in pregnant women and protection against mosquito bites. While several malaria vaccines are under development, none is available yet. Measures aimed at protection against mosquito bites include use of personal protection measures against mosquito bites and vector control measures. These include use of insecticide treated bed nets (ITNs) especially long-lasting insecticidal nets (LLINs), indoor residual spraying (IRS), use of protective nets in windows, doors, ventilators, and eaves to prevent access of mosquitoes, larviciding, and clearing vegetation and containers around houses where mosquitoes harbour and breed [11] [12] [13].

Assessing malaria preventive practices in the high rainfall region of the Niger Delta will ascertain the local malaria situation and help to develop appropriate control measures to advice policy makers and the residents in the subregion with appropriate knowledge of the health problem [1]. This study therefore is aimed at looking at the malaria preventive practices among under-five children in the three Niger Delta states and to compare the differences among them if any.

\section{Methodology}

This was a cross sectional study carried out over a six month period from $1^{\text {st }}$ January to $30^{\text {th }}$ June 2019 in public health facilities in Akwa Ibom, Delta and Rivers states. It is the second arm of the first phase of the Niger Delta Development Company (NDDC) sponsored malaria research on its burden and preventive practices among pregnant women and under-five children being carried out in the nine South-South states of Nigeria. Sample size was calculated using the formula for comparison of groups [14] given as a minimum of 100 under-five 
subjects to be recruited per study site in the Niger-Delta states. The sample size calculation for the study took into account an attrition rate of $10 \%$. Using a stratified sampling method, each of the three states was stratified into three senatorial districts via equal allocation giving a total of nine senatorial districts. In each of the senatorial district, a list of health facilities involved in the care of children constituted the sampling frame. Simple random sampling via computer generated table of random numbers was used to select four health facilities from the sampling frame from each senatorial district giving a total of 12 health facilities from each state and a total of 36 health facilities from the three states. In each study centre, the study was carried out in the Department of Paediatrics within one to two weeks. The first 100 consecutive children who are less than 5 years and whose parents or guardian gave consent for the study were selected. A pretested interviewer administered questionnaire was used to harvest relevant information on socio demographic characteristics of the subjects and informants (age, sex, weight, height, education and occupation), and malaria preventive practices [insecticide treated bed net (ITNs) use, Indoor residual spraying (IRS), antimalarial medicine use, use of mosquito repellents, clearing of bushes and disposal of mosquito breeding containers, presence of window nets in homes]. Obtained data were analysed using SPSS version 22 and results are presented in prose and frequency tables. Chi-square and Fischer's exact was used for comparison of categorical variables, while a p-value of $<0.05$ was considered statistically significant.

\section{Ethical Consideration}

Ethical clearance for the study was obtained from the Research and Ethics committee of the University of Port Harcourt Teaching Hospital (UPTH) before proceeding with the study. Notification and permission to carry out the study was obtained from the Ethics Committee or hospital administration of selected hospitals.

\section{Informed Consent}

All parents and guardians of participating children were informed on all aspects of the study and provided a written informed consent. They were also informed that they were free to withdraw their children from the study at any time.

\section{Result}

\section{Sex and Age distribution of the children from the three states:}

A total of 3600 children were recruited for the study, 456 had incomplete and inconsistent data and were excluded in the final analysis. A total of 3144 children participated in the study giving a response rate of $87.3 \%$. Out of these, 1661 (52.8\%) were males while 1483 (47.2\%) were females. Children less than 2 years represented $77.6 \%$ of the study participants while the mean age was $1.72 \pm 1.06$ years. Table 1 shows that there was a near equal proportion of the male and female participants across the three states with no statistically significant difference $\left(\mathrm{X}^{2}=2.66, p=0.2642\right)$. However, there was a statistically significant 
Table 1. Sex and age distribution of the children from the three states.

\begin{tabular}{|c|c|c|c|c|c|}
\hline State & Akwa Ibom & Delta & Rivers & Total & Chi-square/P value \\
\hline Variable & No (\%) & No (\%) & No (\%) & No (\%) & \\
\hline \multicolumn{6}{|l|}{ Sex of child } \\
\hline Male & $506(50.7)$ & $542(53.8)$ & $613(53.9)$ & $1661(52.8)$ & \multirow{2}{*}{$2.66(0.2642)^{\star \star}$} \\
\hline Female & $492(49.3)$ & $466(46.2)$ & $525(46.1)$ & $1483(47.2)$ & \\
\hline \multicolumn{6}{|l|}{ Age of Child } \\
\hline$<2$ years & $805(80.7)$ & $756(75.0)$ & $879(77.2)$ & $2440(77.6)$ & \multirow{2}{*}{$9.38(0.0092)^{*}$} \\
\hline$>2<5$ years & $193(19.3)$ & $252(25.0)$ & $259(22.8)$ & $704(22.4)$ & \\
\hline Mean age & $\begin{array}{c}1.64 \pm 0.99 \\
\text { years }\end{array}$ & $\begin{array}{c}1.78 \pm 1.10 \\
\text { years }\end{array}$ & $\begin{array}{c}1.74 \pm 1.08 \\
\text { years }\end{array}$ & $\begin{array}{c}1.72 \pm 1.06 \\
\text { years }\end{array}$ & $0.0009^{*}$ \\
\hline
\end{tabular}

${ }^{*}$ Distribution is statistically significant $(\mathrm{p}<0.05)$; ${ }^{*}$ Distribution is not statistically significant $(\mathrm{p}>0.05)$.

difference in the different age groups and the mean age of the participants across the different states $\left(\mathrm{X}^{2}=9.38, p=0.0092\right)$.

\section{Survey Informant (Respondent)}

The modal informant across the three states was the mothers and they constituted over $80 \%$ of the informants in all the states. However, comparing the different informants from the different states showed a statistically significant difference, for example fathers constituted $7.6 \%$ of the informants in Rivers state and only $1.5 \%$ in Delta state (Table 2).

\section{Parents' Educational Level}

Table 3 shows that in Akwa Ibom state, more of the participants had obtained secondary education, among the fathers, there were 492 (49.7\%) and 486 (48.9\%) among mothers; also, in Delta state, more of the participants had obtained secondary education, 559 (56.6\%) and $572(57.1 \%)$ among the fathers and mothers respectively. However, in Rivers state, more of the participants had obtained tertiary education; among the fathers, there were 697 (61.8\%) and 605 (53.4\%) among mothers. These differences in the educational level of the parents were statistically significant when compared among the states. $\left(\mathrm{X}^{2}=210.6, \mathrm{p}\right.$-value $=$ 0.0001 ).

\section{Social Class (Oyedeji's Social class classification) [15]}

Distribution of respondents by social class reveals that the middle social class was most represented in Akwa Ibom and Delta states, constituting 617 (61.8\%) and 617 (61.3\%) respectively. In Rivers state, the upper and middle social class were most represented, constituting 560 (49.4\%) and 548 (48.3\%) respectively. This difference in social class among the respondents across the three states was statistically significant $\left(\mathrm{X}^{2}=175.6, \mathrm{p}=0.0001\right)($ Table 4$)$.

Family's monthly income:

The average family income was 30,000 Naira in Akwa Ibom and Delta states and 50,000 Naira in Rivers state; families that earned above average constituted 32.6\%, 31.7\% and 54.3\% in Akwa Ibom, Delta and Rivers states respectively. This difference in the family monthly income across the states was statistically significant $\left(\mathrm{X}^{2}=216.0, \mathrm{p}=0.0001\right)$ (Table 5). 
Table 2. Survey informant (Respondent).

\begin{tabular}{ccccc}
\hline State & Akwa Ibom & Delta & Rivers & P-value/Fischers exact \\
\hline Variable & No (\%) & No (\%) & No (\%) & \\
\hline Survey Informant & & & & \\
Father & $51(5.1)$ & $15(1.5)$ & $86(7.6)$ & \\
Mother & $920(92.2)$ & $964(95.6)$ & $1012(88.9)$ & \\
Sister & $8(0.8)$ & $7(0.7)$ & $7(0.6)$ & \multirow{4}{*}{$\mathbf{4 7 . 1 5}(\mathbf{0 . 0 0 0 1})^{*}$} \\
Grand Mother & $7(0.7)$ & $10(1.0)$ & $12(1.1)$ & \\
Aunty & $10(1.0)$ & $7(0.7)$ & $14(1.2)$ & \\
Others & $2(0.2)$ & $5(0.5)$ & $7(0.6)$ & \\
\hline
\end{tabular}

${ }^{\star}$ Distribution is statistically significant $(\mathrm{p}<0.05)$.

Table 3. Parents' educational level.

\begin{tabular}{ccccc}
\hline States & Akwa Ibom & Delta & Rivers & Chi-square/P value \\
\hline Variable & N (\%) & N (\%) & N (\%) & \\
\hline Fathers' Education Level & & & & \\
None & $6(0.6)$ & $18(1.8)$ & $6(0.5)$ & \\
Primary & $96(9.7)$ & $49(5.0)$ & $20(1.8)$ & \multirow{2}{*}{ 210.6(0.0001) * } \\
Secondary & $492(49.7)$ & $559(56.6)$ & $405(35.9)$ & \\
Tertiary & $395(39.9)$ & $361(36.6)$ & $697(61.8)$ & \\
Mothers' Education Level & & & & Fischer's exact/P-value \\
None & $3(0.3)$ & $26(2.6)$ & $4(0.4)$ & \\
Primary & $116(11.7)$ & $115(11.5)$ & $35(3.1)$ & \multirow{1}{*}{ 195.4(0.0001) * } \\
Secondary & $486(48.9)$ & $572(57.1)$ & $489(43.2)$ & \\
Tertiary & $389(39.1)$ & $288(28.8)$ & $605(53.4)$ & \\
\hline
\end{tabular}

${ }^{*}$ Distribution is statistically significant $(\mathrm{p}<0.05)$.

Table 4. Social class (Oyedele's social class classification).

\begin{tabular}{|c|c|c|c|c|}
\hline State & Akwa Ibom & Delta & Rivers & Chi-square/P value \\
\hline Variable & No (\%) & No (\%) & No (\%) & \\
\hline \multicolumn{5}{|l|}{ Social Class } \\
\hline Upper Class & $328(32.9)$ & $273(27.2)$ & $560(49.4)$ & \\
\hline Middle Class & $617(61.8)$ & $617(61.3)$ & $548(48.3)$ & $175.6(0.0001)^{*}$ \\
\hline Low Class & $53(5.3)$ & $116(11.5)$ & $26(2.3)$ & \\
\hline
\end{tabular}

${ }^{\star}$ Distribution is statistically significant $(\mathrm{p}<0.05)$.

\section{Malaria prevention techniques practiced in the three states}

The techniques employed in the prevention of malaria the three states included; use of insecticide treated bed net (ITNs), insecticide spray, anti-malarial drugs, clearing of bushes and disposal of mosquito breeding cans and use of mosquito repellents as shown in Table 6. Use of ITN was practiced more in 
Table 5. Family’s monthly income.

\begin{tabular}{ccccc}
\hline State & Akwa Ibom & Delta & Rivers & Chi-square/P value \\
\hline Variable & N (\%) & N (\%) & N (\%) & \\
\hline $\begin{array}{c}\text { Family monthly } \\
\text { income (Naira) }\end{array}$ & & & & \\
$<10,000$ & $252(25.5)$ & $139(14.2)$ & $95(9.5)$ & \\
$10,000-50,000$ & $413(41.8)$ & $528(54.1)$ & $364(36.3)$ & \multirow{2}{*}{$216.0(\mathbf{0 . 0 0 0 1})^{*}$} \\
$50,000-100,000$ & $173(17.5)$ & $197(20.2)$ & $275(27.4)$ & \\
$>100,000$ & $149(15.1)$ & $112(11.5)$ & $270(26.9)$ & \\
Median family income & 30,000 Naira & 30,000 Naira & 50,000 Naira & \\
\hline
\end{tabular}

${ }^{*}$ Distribution is statistically significant $(\mathrm{p}<0.05) .{ }^{* *}$ one Naira equals 360 US dollars.

Table 6. Malaria prevention techniques practiced in the three states.

\begin{tabular}{|c|c|c|c|c|}
\hline State & Akwa Ibom & Delta & Rivers & Fischer's exact \\
\hline $\begin{array}{l}\text { Prevention technique employed } \\
\text { (Multiple response) }\end{array}$ & N (\%) & N (\%) & N (\%) & \\
\hline Use of ITNs & $82(8.2)$ & $205(20.3)$ & $605(53.2)$ & \\
\hline Use insecticide spray & $770(77.2)$ & $567(56.3)$ & $483(42.4)$ & \\
\hline None & $200(20.0)$ & $359(35.6)$ & $182(16.0)$ & \\
\hline Use of drugs-antimalarial & $286(28.7)$ & $134(13.3)$ & $133(11.7)$ & $724.2(0.0001)^{\times}$ \\
\hline $\begin{array}{l}\text { Others (Clearing of nearby bushes, } \\
\text { disposal of mosquito breeding cans) }\end{array}$ & $2(0.2)$ & $1(0.1)$ & $4(0.4)$ & \\
\hline Repellent & $1(0.1)$ & $7(0.7)$ & $2(0.2)$ & \\
\hline \multicolumn{5}{|l|}{ Child slept under bed net last night } \\
\hline No & $931(93.3)$ & $862(85.5)$ & $626(55.0)$ & \multirow{2}{*}{$500.6(0.0001)^{\star}$} \\
\hline Yes & $67(6.7)$ & $146(14.5)$ & $512(45.0)$ & \\
\hline \multicolumn{5}{|l|}{ Have window nets } \\
\hline No & $439(44.0)$ & $319(31.6)$ & $168(14.8)$ & \multirow{2}{*}{$222.0(0.0001)^{\times}$} \\
\hline Yes & $559(56.0)$ & $689(68.4)$ & $970(85.2)$ & \\
\hline
\end{tabular}

ITNs-Insecticide treated bed nets.

Rivers state (53.2\%) than in Delta (20.3\%) and Akwa Ibom (8.2\%) states, while use of insecticide spray was commoner in Akwa Ibom state (77.2\%) than in Delta $(56.3 \%)$ and Rivers $(42.4 \%)$. The difference in the proportion of the different prevention techniques practiced among the states was statistically significant. (Fischer's exact -724.2 , p-value $=0.0001$ )

Relationship between malaria Prevention techniques, social class and family income.

Tables 7-9 show the relationship between malaria prevention techniques, social class and the family income in Akwa Ibom, Delta and Rivers states respectively. In all the states, more people from the middle social class and those within 
Table 7. Relationship between malaria prevention techniques, social class and family income in Akwa Ibom state.

\begin{tabular}{|c|c|c|c|c|c|c|c|}
\hline \multirow{2}{*}{ Variable } & \multicolumn{7}{|c|}{ Prevention techniques } \\
\hline & ITNs & Insecticide sprays & Drugs & None & Repellent & Others & Fishers' Exact/P-value \\
\hline \multicolumn{8}{|l|}{ Social status } \\
\hline Upper class & $18(22.0)$ & $266(34.5)$ & $83(29.0)$ & $101(50.5)$ & $1(100.0)$ & $1(50.0)$ & \multirow{3}{*}{$45.04(0.0001)^{*}$} \\
\hline Middle class & $53(64.6)$ & $471(61.2)$ & $182(63.6)$ & $91(45.5)$ & $0(0.0)$ & $1(50.0)$ & \\
\hline Low class & $11(13.4)$ & $33(4.3)$ & $21(7.3)$ & $8(4.0)$ & $0(0.0)$ & $0(0.0)$ & \\
\hline \multicolumn{8}{|c|}{ Family income (Naira $\left.{ }^{* *}\right)$} \\
\hline$<10,000$ & $18(22.0)$ & $192(25.2)$ & $79(27.7)$ & $15(7.6)$ & $0(0.0)$ & $1(50.0)$ & \multirow{4}{*}{$79.73(0.0001)^{*}$} \\
\hline $10,000-50,000$ & $45(54.9)$ & $299(39.3)$ & $137(48.1)$ & $74(37.4)$ & $0(0.0)$ & $0(0.0)$ & \\
\hline $50,000-100,000$ & $9(11.0)$ & $146(19.2)$ & $34(11.9)$ & $49(24.7)$ & $0(0.0)$ & $0(0.0)$ & \\
\hline$>100,000$ & $10(12.2)$ & $124(16.3)$ & $35(12.3)$ & $60(30.3)$ & $1(100.0)$ & $1(50.0)$ & \\
\hline
\end{tabular}

${ }^{\star}$ Distribution is statistically significant $(\mathrm{p}<0.05) .{ }^{* *}$ one Naira equals 360 US dollars.

Table 8. Relationship between prevention techniques, social status and family income in delta state.

\begin{tabular}{|c|c|c|c|c|c|c|c|}
\hline \multirow{2}{*}{ Variable } & \multicolumn{7}{|c|}{ Prevention techniques } \\
\hline & ITNs & Insecticide sprays & Drugs & None & Repellent & Others & Fishers' Exact/P-value \\
\hline \multicolumn{8}{|l|}{ Social status } \\
\hline Upper class & $26(12.7)$ & $191(33.7)$ & $31(23.1)$ & $98(27.3)$ & $2(28.6)$ & $0(0.0)$ & \multirow{3}{*}{$51.30(0.0001)^{*}$} \\
\hline Middle class & $138(67.3)$ & $334(58.9)$ & $83(61.9)$ & $218(60.7)$ & $5(71.4)$ & $1(100.0)$ & \\
\hline Low class & $41(20.0)$ & $42(7.4)$ & $20(14.9)$ & $43(12.0)$ & $0(0.0)$ & $0(0.0)$ & \\
\hline \multicolumn{8}{|l|}{ Family income } \\
\hline$<10,000$ & $34(17.6)$ & $62(11.1)$ & $41(32.3)$ & $52(14.9)$ & $2(28.6)$ & $0(0.0)$ & \multirow{4}{*}{$70.94(0.0001)^{*}$} \\
\hline $10,000-50,000$ & $123(63.7)$ & $286(51.3)$ & $60(47.2)$ & $174(50.0)$ & $3(42.9)$ & $1(100.0)$ & \\
\hline $50,000-100,000$ & $22(11.4)$ & $124(22.2)$ & $18(14.2)$ & $89(25.6)$ & $2(28.5)$ & $0(0.0)$ & \\
\hline$>100,000$ & $14(7.3)$ & $86(15.4)$ & $8(6.3)$ & $33(9.5)$ & $0(0.0)$ & $0(0.0)$ & \\
\hline
\end{tabular}

${ }^{\star}$ Distribution is statistically significant $(\mathrm{p}<0.05) .{ }^{* *}$ one Naira equals 360 US dollars.

Table 9. Relationship between Prevention technique, social status and family income in Rivers state.

\begin{tabular}{|c|c|c|c|c|c|c|c|}
\hline \multirow{2}{*}{ Variable } & \multicolumn{7}{|c|}{ Prevention techniques } \\
\hline & ITNs & Insecticide spray & Drugs & None & Repellent & Others & Fishers' Exact/P-value \\
\hline \multicolumn{8}{|l|}{ Social status } \\
\hline Upper class & $316(52.2)$ & $287(59.4)$ & $50(37.6)$ & $62(34.1)$ & $0(0.0)$ & $0(0.0)$ & \multirow{3}{*}{$61.41(0.0001)^{*}$} \\
\hline Middle class & $276(45.6)$ & $191(39.5)$ & $75(56.4)$ & $110(60.4)$ & $2(100.0)$ & $4(100.0)$ & \\
\hline Low class & $13(2.1)$ & $5(1.0)$ & $8(6.0)$ & $10(5.5)$ & $0(0.0)$ & $0(0.0)$ & \\
\hline \multicolumn{8}{|l|}{ Family income (N) } \\
\hline$<10,000$ & $44(8.1)$ & $19(4.5)$ & $24(19.8)$ & $21(13.9)$ & $0(0.0)$ & $0(0.0)$ & \multirow{4}{*}{$106.5(0.0001)^{*}$} \\
\hline $10,000-50,000$ & $178(32.8)$ & $119(27.9)$ & $62(51.2)$ & $77(51.0)$ & $2(100.0)$ & $2(50.0)$ & \\
\hline $50,000-100,000$ & $167(30.8)$ & $135(31.7)$ & $23(19.0)$ & $26(17.2)$ & $0(0.0)$ & $2(50.0)$ & \\
\hline$>100,000$ & $153(28.2)$ & $153(35.9)$ & $12(9.9)$ & $27(17.9)$ & $0(0.0)$ & $0(0.0)$ & \\
\hline
\end{tabular}

${ }^{\star}$ Distribution is statistically significant $(\mathrm{p}<0.05) .{ }^{* *}$ one Naira equals 360 US dollars. 
the average monthly income practiced the different prevention methods compared to the lower and upper social classes. There was a statistically significant difference between the malaria prevention techniques practiced and the social class and family income in all the states ( $\mathrm{p}$ value $<0.05$ ).

\section{Discussion}

Malaria prevention and control is a key factor in reduction of infant and under-five morbidity and mortality, so assessment of preventive methods of malaria practiced in any community is a key first step to its control. This study showed that all three states practiced similar malaria preventive methods but with varying proportion and this includes the use of Insecticide treated bed nets (ITNs), insecticide spray, antimalarial drug use, mosquito repellants, clearing of nearby bushes and disposal of mosquito breeding cans.

Unlike in Rivers state where ITNs use (53.2\%) was the commonest malaria preventive practice, the use of insecticide spray (a modified form of indoor residual spraying) was the common practice in Akwa Ibom state (77.2\%) and Delta state $(56.3 \%)$. According to the World Health Organization, the most powerful and widely applied system of control for malaria-carrying insects is the use of insecticides, mostly in the form of insecticide-treated bed nets (ITNs) and indoor residual spraying (IRS) [16]. This modified form of IRS that is commonly practiced among the people of Akwa Ibom and Delta states is usually short lived and requires repeated spraying as its effect wears off in less than 24 hours. This modified form of IRS was also practiced in $42.4 \%$ of residents in Rivers state. Therefore, in this area of stable malaria and malaria holoendemicity, it may not be an effective malaria control measure as its repeated use will be cost intensive. Its effectiveness can only be guaranteed in families that practice its regular use than where it is used irregularly, however, there is limited study in this form of insecticide use to show its effectiveness in malaria vector control.

Use of IRS was however not reported in any of the study sites despite its proven and well-established efficacy in malaria vector control [16]. IRS has been used widely in Asia, the Pacific and Latin America, and it is now being used in Africa. Wagman et al. [17] in an observational study in Mali, reported a 70\% reduction in malaria cases following IRS use and a 70\% increase in under-5 years old malaria incidence when its use was suspended. Akogbeto et al. [18] also reported a dramatic decrease in Malaria transmission after Large-Scale IRS in Benin republic. IRS involves coating the walls and other surfaces of a house with a residual insecticide and for several months, the insecticide will kill mosquitoes and other insects that come in contact with these surfaces as many malaria vectors are considered "endophilic"; that is, the mosquito vectors rest inside houses after taking a blood meal. Since mosquitoes are particularly susceptible to control through IRS, its introduction and use in swampy Niger Delta is advocated.

As noted earlier, use of insecticide treated bed nets (ITNs) is the common malaria preventive method in Rivers state, however, only $20.3 \%$ and $8.2 \%$ of 
families in Delta and Akwa Ibom states respectively practiced this method. ITNs use is an approved, effective and recommended WHO malaria control and preventive method and its proper and consistent use have been shown to reduce malaria transmission by up to $90 \%$ and prevent up to $44 \%$ of all-cause mortality among under-five children [3] [19] [20] [21]. Asides being lower than that in Rivers state, ITNs use rate in Akwa Ibom and Delta states is lower than that from other Nigerian and African studies [22]-[28]. Similar reasons as given by Paul et al. [3] and other study [29] were also given for this low use rate. Programs aimed at increasing the awareness, free donation and distribution and use of ITNs must be promoted in these states. Though its use in Rivers state is high compared to that of other states, it is yet to attain the target observed in some African countries [22] [23] [24] [25] [26] and therefore its ownership and use must also be promoted in Rivers state.

Use of antimalarial prophylaxis is an uncommon practice in children in Nigeria though it's a malaria preventive method recommended by WHO in pregnant women and infants in medium and high malaria transmission areas [30]. It is however practiced among pregnant women, children with sickle cell anaemia (SCA), non-immune visitors to endemic areas and children who have undergone splenectomy. Asides the huge cost implication of a mass antimalarial chemoprophylaxis in infants and children, it is also thought that the acquired immunity that makes severe malaria uncommon in older children may not be attained, hence it's not a common practice. Use of antimalarial drugs is low in this study among the three states and probably represents children with SCA which is quite common in Nigeria.

Other less common methods with lower community malaria prevention effectiveness practiced in less than $1 \%$ in the different states include clearing of bushes, emptying and disposal of containers where mosquitoes breed and use of mosquito repellent creams. Clearing of mosquito breeding places may clear the larval stages of mosquito but is presently a difficult task especially because there is irregular availability of portable water in many homes leading to prevalent dirty and stagnant gutters in many areas. It is also difficult to guarantee the consistent application of mosquito repellent creams by all members of a household or community.

In $16 \%-35.6 \%$ of the participants across the three states, no malaria prevention method was practiced and this cuts across all the social and economic classes. This finding emphasizes the need for creating more awareness on malaria preventive practices to all and sundry in the Niger Delta states. In this study, $56 \%-85.2 \%$ of the participants in the three states had window nets installed in their homes, however, the quality and physical status of these nets cannot be guaranteed as they are not maintained in many homes and so may be a poor vector preventive measure.

More proportion of people in the middle class and those whose monthly income was within the average median income practiced the different methods of 
malaria prevention in the three states, while a lower proportion of people in the lower and upper class practiced any of the methods. High patronage of public hospitals by the middle class where education on ITNs use and its free distribution is done may have contributed to this. Though no social class is exempt from malaria in endemic areas, people from high social class live in cleaner areas of the city, have good protective window and door nets and are likely to have better health seeking behavior compared to those from the lower social class. It is therefore not surprising to have low rates of the malaria prevention methods among them. Lack of awareness and poverty are contributory factors to the low malaria prevention practices among the lower social class and those with low average monthly income. Contributory to this may also be due to the fact that since distribution of these nets mostly takes place in public hospitals which is often less patronised by individuals from the lower class who prefer patronage of quacks due to the huge costs in out of pocket expenditure on health bills they may not own one. This finding is an important one but is worrisome in that those who need these preventive practices the most, practice them the least and hence dying more from malaria. Public health education and refocusing of distribution centres and strategy by using schools, markets and other community gatherings may change this dynamic [3].

\section{Conclusions}

In conclusion, this study has shown that the practice of the two common and effective malaria preventive measures; IRS and ITNs use is low in South-South Nigeria with IRS not being practiced at all. Also, the low practice of ITNs and modified IRS among these states is worse among the lower social class who need it the most.

Introduction of IRS as a method of malaria vector control is advocated in South-South Nigeria. Public health education with emphasis on ITNs ownership and use and refocusing of distribution strategy by using schools, markets and other community gatherings will increase its availability and use among all especially among those who need it the most.

\section{Author's Contribution}

Author 1 wrote the first draft, Author 7 carried out the statistical analysis and results, Authors' 8 and 9 reviewed the first draft. All authors read and approved the final draft and are part of the Niger Delta Development Company (NDDC) Professorial Chair on Malaria Elimination \& Phytomedicine Research, University of Port Harcourt that collected the data.

\section{Limitation of the Study}

Answers provided by the informants in this study were based on recall, and this may affect the validity of the responses. 


\section{Conflicts of Interest}

There is no conflict of interest.

\section{Disclosure/Funding}

The research was funded by the Niger Delta Development Company (NDDC), Nigeria.

\section{References}

[1] Erhun, W.O., Agbani, E. and Adesanya, S.O. (2005) Malaria Prevention: Knowledge, Attitude and Practice in a Southwestern Nigerian Community. African Journal of Biomedical Research, 8, 25-29. http://www.bioline.org.br/md https://doi.org/10.4314/ajbr.v8i1.35755

[2] Paul, N.I., Maduka, O., Chijioke-Nwauche, I., Awopeju, A.T.O., Kasso, T., Oboro, I.L., et al. (2019) Malaria Preventive Practices among Under-Five Children in Rivers State, Nigeria. International Journal of Tropical Disease \& Health, 37, 1-11. https://doi.org/10.9734/ijtdh/2019/v37i330165

[3] World Health Organization (2000) Newsletter, 15, 1-21.

[4] World Health Organisation (2012) World Malaria Report.

[5] Health Protection Agency (HPA) (2011) Migrant Health: Infectious Diseases in Non-UK Born Populations in the UK. An Update to the Baseline Report.

[6] Ekong, E.U. and Angela, E. (2013) Malariometric Indices among Nigerian Children in a Rural Setting. Malaria Research and Treatment, 2013. http://hinari-gw.who.int https://doi.org/10.1155/2013/716805

[7] Babalola, D.A., Olarewaju, M., Omeonu, P.E., Adefelu, A.O. and Okeowo, R. (2013) Assessing the Adoption of Roll Back Malaria Programme (RBMP) among Women Farmers in Ikorodu Local Government Area of Lagos State. Canadian Journal of Pure and Applied Science, 7, 2375-2379.

[8] Okonkwo, C.N.P., Kumar, L. and Taylor, S. (2015) The Niger Delta Wetland Ecosystem: What Threatens It and Why Should We Protect It? African Journal of Environmental Science and Technology, 9, 451-463.

https://doi.org/10.5897/AJEST2014.1841

[9] Winch, P.J., Makemba, A.M., Kamazina, S.R., et al. (1994) Seasonal Variation in the Perceived Risk of Malarial: Implication for Promotion of Insecticide Impregnated Bednets. Social Science \& Medicine, 39, 63-75. https://doi.org/10.1016/0277-9536(94)90166-X

[10] Afolabi, B.M. (1996) Knowledge, Attitude and Practice of Malaria in an Isolated Community on the Atlantic Coast of Lagos.

https://www.google.com.ng/url?sa=t\&rct=j\&q=\&esrc=s\&source=web\&cd=1\&ved =2ahUKEwjfzvuWytHnAhUDxYUKHfg6D 8QFjAAegQIAhAB\&url=https\%3A\% 2F\%2Fwww.researchgate.net\%2Fpublication\%2F301748284 Knowledge Attitude and Practice of Malaria in an Isolated Community on the Atlantic Coast of Lagos Nigeria\&usg=AOvVaw0GSy0ImPVPeCeUOZaUje0q

[11] Walker, K. and Lynch, M. (2007) Contributions of Anopheles Larval Control to Malaria Suppression in Tropical Africa: Review of Achievements and Potential. Medical and Veterinary Entomology, 21, 2-21.

https://doi.org/10.1111/j.1365-2915.2007.00674.x

[12] CDC (2008) Anopheles Mosquitoes. Division of Parasitic Diseases. 
http://www.cdc.gov/malaria/biology/mosquito/

[13] Nganga, P.N., Shililu, J., Jayasinghe, G., Kimani, V., Kabutha, C., Kabuage, L., Kabiru, E., Githure, J. and Mutero, C. (2008) Malaria Vector Control Practices in an Irrigated Rice Agro-Ecosystem in Central Kenya and Implications for Malaria Control. Malaria Journal, 7, Article No. 146. https://doi.org/10.1186/1475-2875-7-146

[14] Kirkwood, B.R. and Sterne, J.A.C. (2003) Essential Medical Statistics. 2nd Edition, Blackwell Science, Oxford, 420-421.

[15] Oyedeji, G.A. (1985) Socioeconomic and Cultural Background of Hospitalized Children in Ilesa. Nigerian Journal of Paediatrics, 12, 111-117.

[16] WHO (2009) Recommended Insecticides for Indoor Residual Spraying against Malaria.

https://www.k4health.org/sites/default/files/WHO\%20 \%20Recommended\%20IRS \%20Insecticides.pdf

[17] Wagman, J., Gogue, C., Tynuv, K., Mihigo, J., Bankineza, E., Mamadou Bah, M., et al. (2018) An Observational Analysis of the Impact of Indoor Residual Spraying with Non-Pyrethroid Insecticides on the Incidence of Malaria in Ségou Region, Mali: 2012-2015. Malaria Journal, 17, Article No. 19. https://doi.org/10.1186/s12936-017-2168-2

[18] Akogbeto, M., Padonou, G.G., Bankole, H.S., Gazard, D.K. and Gbedjissi, G.L. (2011) Dramatic Decrease in Malaria Transmission after Large-Scale Indoor Residual Spraying with Bendiocarb in Benin, an Area of High Resistance of Anopheles gambiae to Pyrethroids. The American Journal of Tropical Medicine and Hygiene, 85, 586-593. https://doi.org/10.4269/ajtmh.2011.10-0668

[19] Lengeler, C. (2004) Insecticide Treated Bednets and Curtains for Preventing Malaria. Cochrane Database of Systematic Reviews, No. 2, CD000363. https://doi.org/10.1002/14651858.CD000363.pub2

[20] Fegan, G.W., Noor, A.M., Akhwale, W.S., Cousens, S. and Snow, R.W. (2007) Effect of Expanded Insecticide-Treated Bednet Coverage on Child Survival in Rural Kenya: A Longitudinal Study. The Lancet, 370, 1035-1039. https://doi.org/10.1016/S0140-6736(07)61477-9

[21] Davis, R.S., Robert, K.D.P. and Macedo, P.A. (2007) An Ecological Risk Assessment for Insecticides Used in Adult Mosquito Management. Integrated Environmental Assessment and Management, 3, 373-382. https://doi.org/10.1897/IEAM 2006-053

[22] Baume, C.A., Reithinger, R. and Woldehanna, S. (2009) Factors Associated with Use and Non-Use of Mosquito Nets Owned in Oromia and Amhara Regional States, Ethiopia. Malaria Journal, 8, Article No. 264. https://doi.org/10.1186/1475-2875-8-264

[23] Gaurav, D., Nidhin, J., Penelope, S.P. and Christine, A. (2014) Malaria-Related Knowledge and Prevention Practices in Four Neighbourhoods in and around Mumbai, India: A Cross-Sectional Study. Malaria Journal, 13, Article No. 303. https://doi.org/10.1186/1475-2875-13-303

[24] Mazigo, H.D., Obasy, E., Mauka, W., Manyiri, P., Zinga, M., Kweka, E.J., et al. (2010) Knowledge, Attitudes, and Practices about Malaria and Its Control in Rural Northwest Tanzania. Malaria Research and Treatment, 2010, Article ID: 794261. https://doi.org/10.4061/2010/794261

[25] Luyiga, F.M. (2013) Knowledge, Attitudes and Practices on Malaria Prevention and Control in Uganda.

http://www.library.health.go.ug/publications/sevice-delivery-disease-control-preven $\underline{\text { tioncommunicable-disease/malaria/knowledge-19 }}$ 
[26] Tadele, G., Gebremariam, H. and Asegedech, W. (2017) Factors Affecting Prevention and Control of Malaria among Endemic Areas of Gurage Zone: An Implication for Malaria Elimination in South Ethiopia. Tropical Diseases, Travel Medicine and Vaccines, 3, 17. https://doi.org/10.1186/s40794-017-0060-2

[27] Nwokeukwu, H.I., Emma-Ukaeghu, U., Inya-Agha, D. and Iwuoha, E.C. (2014) Use of Insecticide Treated Bed Nets amongst Public Health Physicians in Nigeria. Journal of Dental and Medical Sciences, 1, 73-77. https://doi.org/10.9790/0853-13197377

[28] Udonwa, N.E., Gyuse, A.N. and Etokidem, A.J. (2010) Malaria: Knowledge and Prevention Practices among School Adolescents in a Costal Community in Calabar, Nigeria. The African Journal of Primary Health \& Family Medicine, 2, 103-107. https://doi.org/10.4102/phcfm.v2i1.103

[29] Kilian, A., Byamukama, W., Pigeon, O., Atieli, F., Duchon, S. and Phan, C. (2008) Long-Term Field Performance of a Polyester-Based Long-Lasting Insecticidal Mosquito net in Rural Uganda. Malaria Journal, 7, Article No. 49.

https://doi.org/10.1186/1475-2875-7-49

[30] Greenwood, B. (2010) Anti-Malarial Drugs and the Prevention of Malaria in the Population of Malaria Endemic Areas from 5th Multilateral Initiative on Malaria Pan-African Malaria Conference Nairobi, Kenya. Malaria Journal, 9, S2.

http://www.malariajournal.com/content/9/S3/S2

https://doi.org/10.1186/1475-2875-9-S3-S2 